\title{
Self-Reported Reading Strategies of U.S. College Students and Implications for Institutions of Higher Education
}

\author{
Carrie Anna Courtad Ph.D. \\ Department of Special Education \\ Illinois State University \\ USA \\ Catherine Wigent, Ph.D. \\ Oakland University \\ School of Education and Human Services
}

\begin{abstract}
Little is known about the metacognitive strategies college students are using for university level reading and discipline specific reading. As students progress through their education and become more skilled in their respective fields, their reading strategies should improve and be more flexible according to research that indicates that older, more experience readers have more evolved and flexible reading strategies (Pressley \& Lundberg, 2008) This study focuses on the self-reported strategies used by college students in relation to the expert reader. A mass invitation to participate in the survey Metacognitive Awareness of Reading Strategies Inventory (MARSI) developed by Mokhtari and Reichard (2002) was sent to a large public university in the Midwest. The MARSI is intended to measure the self-reported reading strategies used for academic reading and was validated with adolescent and adult readers (2002).This study examines the self-reported reading strategies of U.S. college students to determine if field of study or number of college credits impacted their use of reading strategies. These results indicated statistically significant differences in the reading strategies used by students' disciplines.
\end{abstract}

Keywords: met cognition in reading, college students, adolescent readers, expert reading

\section{Introduction}

In the United States, forty-two states and the District of Columbia have accepted Common Core Standards initiative with full implementation in the upcoming years (Achieve, 2013). The reasoning behind instituting Common Core Standards is to prepare students for the rigors of university and work when graduating from grade twelve. The Common Core was "designed to be robust and relevant to the real world, reflecting the knowledge and skills that our young people need for success in college and careers" (Mission Statement. n.d.).Reading ability plays an important role in the success of post school outcomes for undergraduate students due to the variety of complicated print material that is encountered beyond grade twelve.

University students are inundated with print material in multiple forms. Students must be capable of managing and comprehending the information presented to them within the classroom and beyond its boundaries. According to reports from the ACT, Inc., high school students (ages 14-18) who meet the ACT benchmarks (a score of 21 on ACT exam) are likely to have better outcomes including, enrollment in college, higher grades in college courses their first year, and better retention rates (ACT, Inc. 2006). Students who achieve at least a 21 are deemed proficient readers, and are less likely to need remediation when they attend university (ACT, Inc. 2006). However, we know little about the particular rmetacognitive strategies the students are using for university level reading and discipline specific reading. These undergraduate students, who are considered proficient readers by meeting the benchmark, use multiple reading strategies in order to navigate the host of textual information on a daily basis. As students progress through their education and become more skilled in their respective fields, their reading strategies should improve and be more flexible according to research that indicates that older, more experience readers have more evolved and flexible reading strategies (Pressley \&Lundberg, 2008; Veenman \& Spaan, 2005). 


\section{Met cognition in Reading}

Metacognition monitors and regulates thinking, and is generally believed to be an important construct of proficient reading (Mokhtari \& Reichard, 2002). For example, Baker(1989) found in her study of adult readers that the more proficient readers were more aware of their own comprehension and better able to control the monitoring of their comprehension. Baker further asserts that better readers were more metacognitively aware than the less proficient readers (1989). Young children along with less proficient readers have been shown to be less apt to monitor their own comprehension or understanding of a passage, and to focus more on the decoding process (Mokhtari \& Reichard, 2002; Paris \& Winograd, 1990). Metacognition and comprehension monitoring are used by proficient readers (Cromley \& Azevedo, 2006; Pressley \& Afflerbach, 1995). Thus a measure of students' metacognition while reading can shed light on the reading process that the students are engaged in while reading. Additionally, metacognition of reading can be a marker of undergraduate students' proficiency of comprehending written material. Metacognition and comprehension monitoring are important pieces in the picture of proficient reading.

Metacognition is thought to develop across the life span with children as young as preschoolers demonstrating some ability to plan and reflect (Alexander, Carr, \& Schwanenflugel, 1995; Veenman, Van Hout-Wolters, \& Afflerbach, 2006). In Veenman and Spaans' (2005) study of elementary students, they found that metacognition skills increased with age. Additionally, adults demonstrate more metacognitive skill than young children(Kuhn, 2000). Students are thought to develop general knowledge of metacognition and move toward having greater ability to control and use metacognitive strategies (Veenman et al., 2006).

Multiple studies have found that expert readers are highly flexible in their reading strategy use and demonstrate metacognitive awareness of their own reading, adjusting their reading strategies as needed to maximize reading comprehension (Lundeberg, 1987; Pressley \& Afflerbach, 1995; Pressley \& Lundeberg, 2008; Wineburg, 1991). However, the studies on expert readers were done with material from the expert readers' area of expertise. For instance, Wineburg's (1991) study with historians and Lundeberg's (1987) study of lawyers both highlight the advanced strategic reading abilities of the experts in their own fields. One would expect to see university students using more reading strategies as they move toward becoming more proficient in their fields of study.

In general, it is unclear whether metacognition is discipline specific with discipline referring to the reading purpose such as reading for information or analyzing the text(Veenman et al., 2006). However, when examining metacognition, there are some metacognitive acts that lend themselves to various academic activities such as reading a text versus problem solving (2006). Not all text is read with the same goal or task in mind; students may read a text to gain knowledge or to critique or analyze the information in the text. It is thought that as students mature, their metacognitive abilities do as well, and perhaps, their use of metacognitive strategies becomes more discipline specific (2006).

Shanahan and Shanahan (2008)assert that experts from different fields such as math, chemistry and history use different strategies when reading text from within those fields suggesting that students must be prepared to read and think about text from different fields in different ways. When conceptualizing literacy in this way, disciplinary specific literacy is both essential and the most advanced form of literacy. Direct instruction on strategies for reading discipline specific text may be warranted for university students (2008). The purpose of this study was to investigate the self-reported reading strategies of undergraduate students to examine their strategy use by discipline and to determine if their reading strategy use changed as they progressed in university.

\section{Purpose}

The theoretical framework for this study is based on Pressley and Afflerbach's (1995) framework for constructively responsive reading. Pressley and Afflerbach assert that reading is highly complex and comprised of multiple processes that overlap including constructing knowledge, monitoring for understanding, and evaluating. In order for a reader to be effective, he/she must engage in all of these processes as needed in order to comprehend the task. For instance, readers who are constructing knowledge, may engage in such processes as taking notes, previewing the text, and summarizing or paraphrasing the text. Readers engaged in monitoring for understanding are aware when they do not understand the text and demonstrate such strategies as; adjusting the reading rate, self-questioning to check for understanding, or rereading difficult text. Good readers are also able to evaluate the text by determining if the text suits their reading purpose, as well, as analyzing and evaluating conflicting information. 
These reading processes are not singular or individual but intertwined and connected. Good readers are metacognitive of the strategies they use and use a variety of strategies to meet their reading goals. This study examined the following questions:

3.1 As students obtain more experience in their university studies, does their report of using reading strategies change?

3.2 Are there differences between field of study and self reported reading strategies?

\section{Methodology}

The survey was conducted at a large national university in the Midwest. College students were the target audience for this study. At the time of the survey, the institution had an undergraduate population of 18, 207, with an average beginning ACT score of 23. 7, which was beyond the ACT benchmark of 21. The majority of the population was female $(55.6 \%)$ and $16.5 \%$ were representative of minority groups(University 2012 Fact Book, 2012).

\subsection{Procedure}

A mass request for participation email was sent to the undergraduate population through university email addressesto those who had given permission to be contacted for research purposes. The email included a description of the study and a link to the survey. When removing email addresses of students who had denied permission to be contacted, or email addresses that were deemed as undeliverable, emails were sent to 17, 368 undergraduate students. Email requests for participation were sent three times in the fall semester, August, September and October.

\subsection{Instrumentation}

The instrument used for this study was a survey that included the Metacognitive Awareness of Reading Strategies Inventory (MARSI) developed by Mokhtari and Reichard (2002). The MARSI is intended to measure the selfreported reading strategies used for academic reading and was validated with adolescent and adult readers (2002). The MARSI consists of 30 statements and is broken down into three subscales: 1) Global reading strategies include setting purpose, activating prior knowledge, predicting, previewing, using text structure and using context clues, 2) Problem-solving strategies include adjusting reading rate, visualizing, guessing meaning of unknown words and 3) Support reading strategies include, paraphrasing, self-questioning, and summarizing (2002). The Internal consistency reliability coefficients by Cronbach's alpha for the MARSI and subscales is as follows; Global Reading Strategies (.92), Problem Solving Strategies (.79), Support Strategies (.87), with an overall reliability of (.93) (Mokhtari \& Reichard, 2002; Sheorey \& Mokhtari, 2002). Participants were asked to rate 30 statements using a 1-5 Likert rating scale. The following Likert scale score was weighted for each of the statements:

1.Never/almost never means "I never or almost never do this when reading school-related material"

2. Occasionally means "I do this only occasionally when reading school-related material"

3.Sometimes means "I sometimes do this when reading school-related material (about 50\% of the time).

4.Usually means "I usually do this when reading school-related material."

5.Always means "I always or almost always do this when reading school-related material."

The survey also included demographic information of the students including, the number of credit hours they had completed prior to the fall semester, which college the major of study was housed in, and preference for reading college assignments. While completing the MARSI, participants were reminded to respond to the rating scale while thinking about college-level expository reading material.

\subsection{Participants}

Of the emails that were sent, 326 students followed the link and logged onto the survey. This resulted in just under a $2 \%$ return rate, considered low for the potential population. Holbrook, Krosnick, and Pfent(2007) suggest that a low return rate only minimally affects the accuracy, and the results could be considered somewhat generalizable to the institution. Incomplete cases were removed if they had failed to complete the Likert scale on reading strategies. There were five colleges in the university represented along with an additional category of undeclared. Participants who resided in the college of Fine Arts represented majors in theatre, music, and dance. Those participants in the college named Business represented majors in accounting, finance, and marketing. Special education, elementary and secondary education majors represented the college named Education. 
The college category of Applied Tech housed majors such as agriculture, criminal justice, pre-veterinarian medicine, and computer science. The college named Arts \& Sciences represented students with majors in languages, literature, history, politics, and communication. The participants, categorized asundeclared indicated they had yet to choose a major. Break down by the number of participants by college is indicated in Table 4.1.

\section{Table 4.1Participant by College}

\begin{tabular}{llll}
\hline College & N & \% & \\
\hline \hline Fine Arts & 19 & 7.4 & \\
Business & 27 & 10.5 & \\
Education & 80 & 31.3 & \\
Applied Tech & 30 & 11.7 & \\
Arts \& Science & 80 & 31.3 & \\
Undeclared & 20 & 7.8 & $\mathbf{1 0 0 \%}$ \\
Total & $\mathbf{2 5 6}$ & & $\mathbf{1 0 0}$
\end{tabular}

The year in school was figured by looking at the number of credit hours the participant self reported they had accumulated prior to the start of the fall semester. The participants were representative of four categories: $37 \%$ freshman $(n=94), 15 \%$ sophomores $(n=39), 22 \%$ juniors $(n=56)$, and $26 \%$ seniors $(n=67)$.

\section{Results}

The Likert score answers of how the participants rated their reading strategies were gathered from the survey. The overall means were calculated for the three subscales of the MARSI. The means for subscales were then compared in several ways. First the scores were compared by the year the student indicated they were in school. After reviewing how the students answered by year, a statistical analysis was conducted to discover if there were any significant differences in the reported means by year in school. The same process was completed for comparing the means of the three subscales by college. The results of the overall means by subscale as well as the comparison of means by year and means by college of major are discussed in the next section.

\subsection{Subscale Comparison}

Overall there were significant differences between the means of the three subscales for the MARSI. When reviewing overall means for participants, all ages reported more often using Problem Solving Strategies with an overall mean of 3.75, meaning they sometimes to usually, employed these types of strategies when reading university assignments. Mokhtari and Reichard (2002) would indicate that this is a "high" answer (p.254). Example statements from the Problem Solving subscale include: I read slowly but carefully to be sure I understand what I'm reading, I try to picture or visualize information to help remember what I read, or When text becomes difficult, I reread to increase my understanding. The overall reported mean for the subscale of Global Reading was 3.35 and according Mokhtari and Reichard (2002)is within the "medium" answer range of 2.5-3.4 (p. 255). Example statements of the Global Reading Subscale include: I skim the text first by noting characteristics like length and organization, I use context clues to help me better understand what I'm reading, or I critically analyze and evaluate the information presented in the text. Lastly the overall reported mean for Support Strategies was 2.84, which is still within the medium answer range. Example statements of Support Reading Strategies include: I take notes while reading to help me understand what I read, I use reference materials such as dictionaries to help me understand what I read, or I paraphrase (restate ideas in my own words) to better understand what I read. Please review Figure5.1 for means of each subscale by year in school and overall.

\subsection{Year in School}

When reviewing the MARSI subscores by year in school, there appeared to be very little difference based on the year in school. Each age group reported similar strategy use to that of the overall student strategy use (see Figure5.1). 
Figure 5.1MARSI mean sub scores overall and by year in school

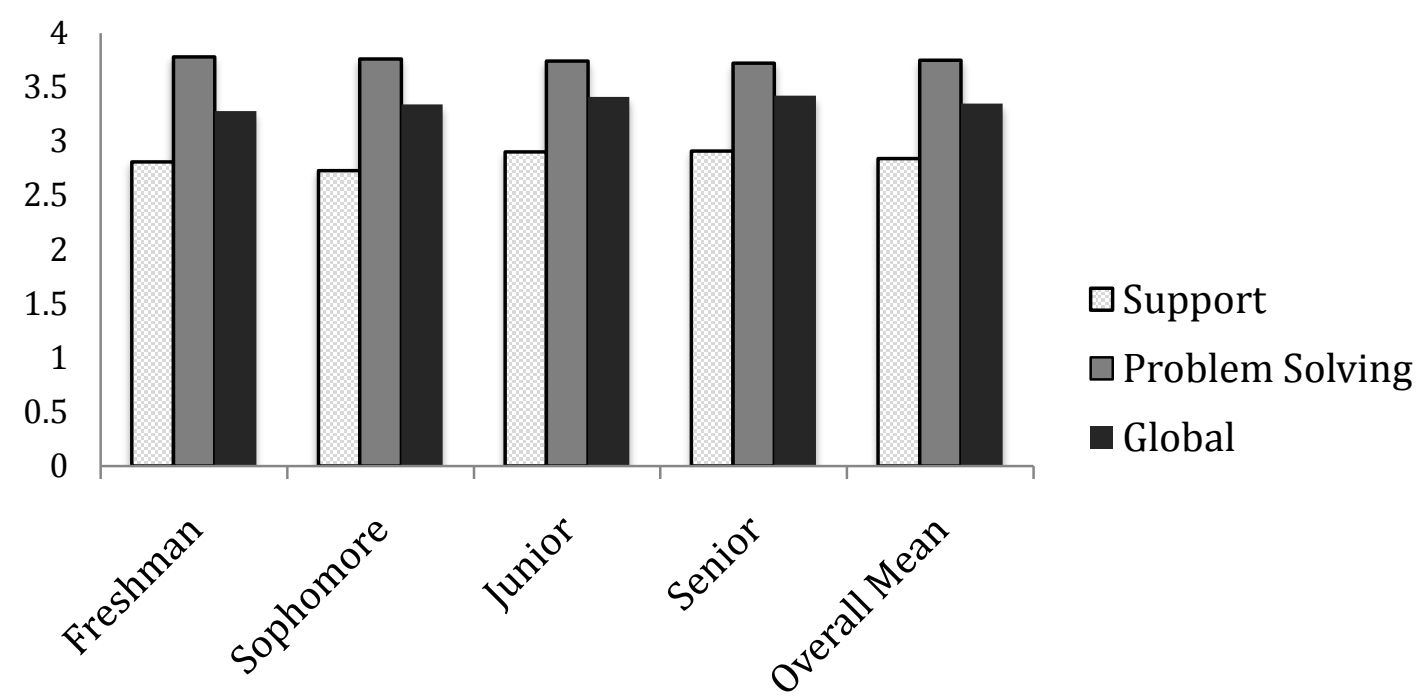

In regards to the question; as students obtained more college education did their reported use of reading strategies change, the authors hypothesized that as students became more mature in their studies, the reported reading strategies would change in relation to their year in school. Participants reported credit hours completed to obtain a year in school. The means of the three MARSI subscales were compared to the year in school using a MANOVA. There were no significant differences noted by the year in school, implying that students reported using the same strategies with the same amount of frequency regardless of their year in school.

\subsection{College of Major}

To answer the question; are there significant differences in the self reported reading strategies based on field of study, investigators looked at the college associated with the reported major and the means of each subscale of the MARSI. Before running statistical analyses comparing the means of the three subscales by the college, the means were charted. See figure 5.2 to review the responses of the participants on the three subscales grouped by the major college.

Figure 5.2Means of Subscales for college of major

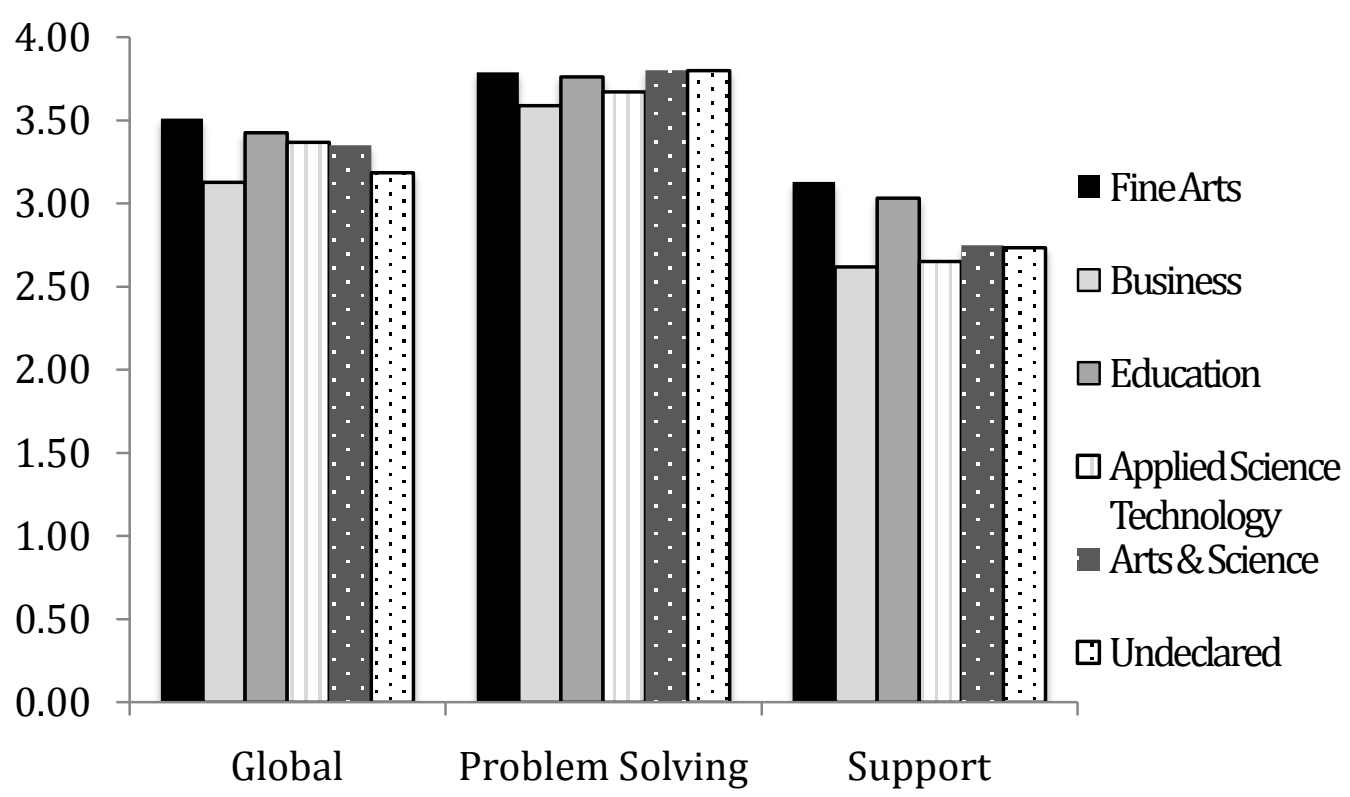


When comparing means of the three MARSI subscales, significant differences in two of the subscales among several colleges emerged. There were significant differences in the subscale called Global Strategies, which includes such strategies as, I have a purpose in mind when I read, I preview, I skim first, I decide what to read closely and what to ignore, and I use tables and figures. The students from the college labeled Business reported using these strategies significantly less $(\alpha=.05)$ than the students from the colleges of Fine Arts and Education. There were also significant differences in the subscale Support Strategies, which includes strategies such as, I take notes, I read the difficult passages out loud, I circle or underline, I use reference materials, and I ask myself questions. Means of the participants in the Fine Arts category reported using significantly more of these strategies than the participants in Business, Applied Science \&Technology, and Arts \& Science. Additionally, means for participants in the college labeled Education reported using significantly more Support Strategies than the participants in the college labeled Business as well as the college labeled Applied Science \& Technology. See table 5.2 for mean differences and significances.

Table 5.2Significant Differences Among Colleges and MARSI Subscales

\begin{tabular}{|c|c|c|c|c|c|}
\hline Strategy & College M & & Mean & Std. & Sig \\
\hline GLOBAL & $\begin{array}{l}\text { Business } \\
(\mu=3.13)\end{array}$ & $\begin{array}{l}\text { Fine Arts } \\
(\mu=3.51)\end{array}$ & $-.3819^{*}$ & $\begin{array}{l}.1800 \\
8\end{array}$ & .035 \\
\hline & & $\begin{array}{l}\text { Education } \\
(\mu=3.42)\end{array}$ & $-.2963^{*}$ & $\begin{array}{l}.1340 \\
6\end{array}$ & .028 \\
\hline $\begin{array}{l}\text { SUPPOR } \\
T\end{array}$ & $\begin{array}{l}\text { Fine Arts } \\
(\mu=3.13)\end{array}$ & $\begin{array}{l}\text { Business } \\
(\mu=2.61)\end{array}$ & $.5114^{*}$ & $\begin{array}{l}.2132 \\
7 \\
\end{array}$ & .017 \\
\hline & & $\begin{array}{l}\text { Applied } \\
\text { Science } \\
\text { Technology } \\
(\mu=2.65) \\
\end{array}$ & $.4784^{*}$ & $\begin{array}{l}.2132 \\
7\end{array}$ & .026 \\
\hline & & $\begin{array}{ll}\text { Arts } & \& \\
\text { Science } & (\mu \\
=2.73) & \end{array}$ & $.3948^{*}$ & $\begin{array}{l}.1815 \\
5\end{array}$ & .031 \\
\hline & $\begin{array}{l}\text { Education } \\
(\mu=3.03)\end{array}$ & $\begin{array}{l}\text { Business } \\
(\mu=2.61)\end{array}$ & $.4137^{*}$ & $\begin{array}{l}.1587 \\
7\end{array}$ & .010 \\
\hline & & $\begin{array}{l}\text { Applied } \\
\text { Science } \\
\text { Technology } \\
(\mu=2.65)\end{array}$ & $.3807^{*}$ & $\begin{array}{l}.1587 \\
7\end{array}$ & .017 \\
\hline
\end{tabular}

\section{Discussion}

\subsection{Subscales}

When reviewing the overall results, it did appear that students rated themselves least likely to use reading strategies included in the Supported Reading Strategies subscale. These items asked if students ever wrote down summaries or used outside material to help them understand material. If a reader follows a hyperlink or online dictionary while reading online they would in essence be using outside material. However, students reported using those strategies less, regardless of year in school or college of major. Students reported using strategies from the Problem Solving subscale with the most frequency. These strategies include items such as slowing down, rereading if the material is difficult, and using visualization. Most of these strategies require that the students are aware that they do not comprehend the reading and generally require the reader to change tactics, such as slowing down or rereading in order to better comprehend. It is encouraging that college level students are using these strategies when faced with challenging expository text. Good readers often interact with text in this way versus focusing on reading quickly (Pressley \& Afflerbach, 1995).

\subsection{Year in school}

Previous research from expert readers indicates expert readers interact with text more than non-expert readers(Lundeberg, 1987; Simmo b ns, Lanuza, Fonteyn, Hicks, \& Holm, 2003; Wineburg, 1991). 
The authors hypothesized there would be a statically significant difference among the age groups of college students and how they reported their reading strategies similar to Veenman and Spaans'(2005) study. However, no significant differences were found between years in school and reported reading strategy use. It was theorized that as students become more comfortable with their discipline, they would begin to look more like expert readers, and therefore, they would report interacting with college reading assignments differently, especially in students who were seniors versus freshman. This was not the case. There were no differences between age and reported strategies, indicating that the reported reading strategies of college age students do not change over their time at the university.

Several possibilities exist for these findings. It is possible that student rely on the reading strategies they already posses when they arrive on campus and continue to use those strategies throughout their undergraduate academic career. Or perhaps seniors are still neophytes in their academic learning despite four years of college credit, and do not use the reading strategies that experts might use. Lastly, it is possible the students do not know how to use these strategies, however, this seems unlikely since they still report that at times they use all the strategies, however, not to the extent or focus one would expect from expert readers.

\subsection{Discipline Specific}

Participants who are studying in the colleges of Fine Arts and Education reported more use of Global Strategies than those majors in the Business college. For the subscale of Support Strategies there were several significant differences noted. Fine Arts student reported using those strategies more frequently than Business, Applied Science and Technology and Arts and Science.

Perhaps the discipline dictates how a college age student approaches traditional text when reading for a class. Those in Fine Arts are approaching traditional text differently than Business, Applied Science \& Technology and Art and Science. In Fine Arts as a discipline, texts are interpreted and analyzed as a whole and often reviewed for common themes or symbolism. Reviewing the text for themes perhaps lends itself to strategies from the subcategory of Support Strategies in the MARSI, including summarizing and paraphrasing. In a sense the students in Fine Arts are problem solving as they read and have to analyze the text giving them more practice with support strategies as part of their course of study. Whereas, in Business, Applied Science \& Technology, and Arts and Sciences, texts tend to require the reader to focus on gaining knowledge from the text versus critiquing or analyzing the text. During this type of reading task, students may focus more on the main ideas and details of the text by focusing on titles, vocabulary, and text structure. This is significant for educators because reading strategies are not generically useful, and students struggling with text from a specific field such as science, technology or math may benefit from specialized reading strategy instruction.

\subsection{Limitations}

There are some limitations with this study, as with most survey studies, this is only survey. An assumption has to be met that students are giving their best most honest answer. The low turn out was disappointing and perhaps more efforts could be made for recruiting participants, however, this assured that there was no "prize" bias, meaning that participants answered truthfully without coercions for a prize. This survey may not be sensitive enough to capture changes in metacognition. Perhaps changes are happening, however this instrument is inefficient at capturing these changes. Grouping students by colleges is not always a clean way to discuss discipline. Some colleges house a large variety of majors and departments that may approach reading tasks very differently yet they all fall under the same college. However, in order to determine if there were initial differences between disciplines, the college groupings were useful. In the future, it may be beneficial to look at other ways of grouping students.

\section{Conclusion}

The major points for consideration are that the discipline area or college did have significant differences in reported reading strategy use while the year in school did not show significant differences in reported reading strategy use. This appears to be counterintuitive to what would be expected based on previous literature. As college students become more ingrained in their discipline, one would expect them to start to demonstrate an expertise in their area of study. Because of this expertise, one would assume that they would look more like expert readers in previous studies. However, in this study, year in school did not impact the reported reading strategies of college students. All students regardless of the year in school reported using the same reading strategies in the same manner. It appears that discipline or the type of reading required had a bigger impact than year in school. 
This study contributes to the literature on metacognition and domain by highlighting some differences with fields of study at the university level. This warrants further investigation to determine if targeted instruction for different types of texts and tasks would be helpful at the undergraduate level. All reading tasks are not the same; reading is a high complex activity that can be undertaken to gain knowledge or insight, to examine or problem solve, or for pure enjoyment. Fully understanding the importance of matching reading tasks with reading strategies could inform instruction; especially for students who may struggle with reading text from a specific discipline or one that requires a specific task.

While it is believed that very young children can be metacognitive and that metacognition improves with age, this study did not show a window of improvement within the four years of undergraduate study. This would not imply that undergraduate students are done maturing with respect to metacognition, but that there needs to be further study to determine how this growth in metacognition with regards to reading manifests itself in postsecondary education. While the assumption is that undergraduates come to the university with a degree of reading ability, are there strategies that can be used at the postsecondary level to further enhance reading toward an expert level? Finally, this study begins to consider how proficient undergraduate readers tackle complex university and domain specific text. The Common Core Standards emphasize reading material that is more complex and varied, and that develops deeper knowledge across grades (National Governors Association Center for Best Practices and Council of Chief State School Officers, 2010). As students are expected to read and comprehend more complex text, it becomes imperative that educators understand the processes used by proficient readers when reading such text. This study demonstrates the potential variation of reading strategies used across domains, and may be useful in informing effective instruction of domain specific strategies for reading complex text.

\section{References}

Achieve, Closing the Expectations Gap: 2013 Annual Report on the Alignment of State K-12 Policies and Practice with the Demands of College and Careers (Washington, D.C.: Achieve, 2013).

ACT, Inc. (2006). Reading between the lines: What the ACT reveals about college readiness in reading and work. Iowa City, IA: Author.

Alexander, J. M., Carr, M., \& Schwanenflugel, P. J. (1995). Development of metacognition in gifted children: Directions for future research. Developmental Review, 15, 1-37.

Baker, L. (1989). Metacognition, comprehension monitoring, and the adult reader. Educational Psychology Review, $1(1), 3-38$.

Cromley, J. G., \& Azevedo, R. (2006). Self-report of reading comprehension strategies: What are we measuring? Metacognition Learning, 1, 229-247.

Holbrook, A., Krosnick, J., \& Pfent, A. (2007). The causes and consequences of response rates in surveys by the news media and government contractor survey research firms. In J. M. Lepkowski, N. C. Tucker, J. M. Brick, E. D. DeLeeuw, L. Japec, P. J. Lavrakas, M. W. Link \& R. L. Sangster (Eds.), Advances in telephone survey methodology. New York: Wiley.

Kuhn, D. (2000). Metacognitive development. Current Directions in Psychological Science, 9(5), 178-181.

Lundeberg, M. A. (1987). Metacognitive aspects of reading comprehension: Studying understanding in legal case analysis. Reading Research Quarterly, 22, 407-432.

Mission Statement. (n.d.). Common Core State Standards Initiative. Retrieved December 1, 2013, from www.corestandards.org

Mokhtari, K., \& Reichard, C. A. (2002). Assessing students' metacognitive awareness of reading strategies. Journal of Educational Psychology, 94(2), 249-259.

National Governors Association Center for Best Practices \& Council of Chief State School Officers. (2010). Common Core State Standards. Washington, DC: Authors.

Paris, S. G., \& Jacobs, J. E. (1984). The benefits of informed instruction for chilren's reading awareness and comprehension skills. Child Development, 55, 2083-2093.

Paris, S. G., \& Winograd, P. (1990). How metacognition can promote academic learning and instruction. In B. F. Jones \& L. Idol (Eds.), Dimensions of thinking and cognitive instruction (pp. 15-51). Hillsdale, NJ: Erlbaum.

Pressley, M., \& Afflerbach, P. (1995). Verbal Protocols of Reading: The Nature of Constructively Responsive Reading. Hillsdale, New Jersey: Lawrence Erlbaum Associates. 
Pressley, M., \& Lundeberg, M. (2008). An invitation to study professionals reading professional-level text: A window on exceptionally complex flexible reading. In K. B. Cartwright \& O. D. Gedeon (Eds.), Literacy Processes: Cognitive Flexibility in Learning and Teaching (pp. 165-187). New York: Guilford Press.

Shanahan, T., \& Shanahan, C. (2008). Teaching disciplinary literacy to adolescents: Rethinking content-area literacy. Harvard Edcuational Review, 78(1), 40-61.

Sheorey, R., \& Mokhtari, K. (2002). Measuring ESL students' awareness of reading strategies. Journal of Developmental Education, 25(3), 2-10.

Simmons, B., Lanuza, D., Fonteyn, M., Hicks, F., \& Holm, K. (2003). Clinical Reasoning in Experienced Nurses. Western Journal of Nursing Research, 25(701-719).

University 2012 Fact Book. (2012). Planning, Research, and Policy Analysis, XXXXX XXXXXX University Retrieved March15, 2013, from http://prpa.XXXXXXXXXX.edu/downloads/1213_factbook/Book.pdf\%3Chttp://prpa.XXXXXXX.edu/downloads/12-13_factbook/Book.pdf

Veenman, M. V. J., \& Spaans, M. A. (2005). Relation between intellectual and metacognitive skills: Age and task differences. Learning and Individual Differences, 15, 159-176.

Veenman, M. V. J., Van Hout-Wolters, B., \& Afflerbach, P. (2006). Metacognition and learning: Conceptual and methodological considerations. Metacognition Learning, 1(1), 3-14.

Wineburg, S. S. (1991). On the reading of historical texts: Notes on the breach between school and academy. American Educational Research Journal 28, 495-519. 